Original article

\title{
Relation between plasma antioxidant vitamin levels, adiposity and cardio-metabolic profile in adolescents: Effects of a multidisciplinary obesity programme
}

\author{
Marcela Guerendiain ${ }^{\mathrm{a}, \mathrm{b}}$, Jordi Mayneris-Perxachs ${ }^{\mathrm{a}}$, Rosa Montes ${ }^{\mathrm{a}}$, , \\ Gemma López-Belmonte ${ }^{c}$, Miguel Martín-Matillas ${ }^{\mathrm{d}, \mathrm{e}}$, Ana I. Castellote ${ }^{\mathrm{a}, \mathrm{f}}$, \\ Elena Martín-Bautista ${ }^{\mathrm{d}}$, Amelia Martí ${ }^{\mathrm{f}, \mathrm{g}}$, J. Alfredo Martínez ${ }^{\mathrm{f}, \mathrm{g}}$, Luis Moreno ${ }^{\mathrm{h}}$, \\ Jesús $\mathrm{M}^{\mathrm{a}}$ Garagorri ${ }^{\mathrm{h}}$, Julia Wärnberg ${ }^{\mathrm{i}}$, Javier Caballero ${ }^{\mathrm{j}}$, Ascensión Marcos ${ }^{\mathrm{i}}$, \\ M. Carmen López-Sabater ${ }^{\mathrm{a}, \mathrm{f}, \text {, }}$, Cristina Campoy ${ }^{\mathrm{c}, \mathrm{d}, \mathrm{k}}$, EVASYON Study Group \\ a Department of Nutrition and Food Science, Faculty of Pharmacy, University of Barcelona, Barcelona, Spain \\ ${ }^{\mathrm{b}}$ University of the Republic, Montevideo, Uruguay \\ c Instituto de Investigación Biosanitaria (Ibs Granada), Department of Paediatrics, University of Granada, Granada, Spain \\ ${ }^{\mathrm{d}}$ EURISTIKOS Excellence Centre for Paediatric Research, Granada, Spain \\ e Department of Physical Education and Sport, School of Sport Sciences, University of Granada, Spain \\ ${ }^{\mathrm{f}}$ CIBER Physiopathology of Obesity and Nutrition (CIBEROBN), Institute of Health Carlos III, Spain \\ ${ }^{g}$ Department of Nutrition, Food Science, Physiology and Toxicology, University of Navarra, Pamplona, Spain \\ ${ }^{\mathrm{h}}$ Department of Paediatrics, Radiology and Physical Medicine, University of Zaragoza, Spain \\ i Department of Metabolism and Nutrition, Institute of Food Science, Technology and Nutrition (ICTAN), Spanish National Research Council (CSIC), Madrid, \\ Spain \\ j Biochemical Service, Hospital Reina Sofía, Córdoba, Spain \\ k CIBER de Epidemiología y Salud Pública (CIBERESP), Granada, Spain
}

\section{A R T I C L E I N F O}

Article history:

Received 25 May 2015

Accepted 1 November 2015

\section{Keywords:}

Plasma antioxidant vitamins

Plasma carotenoids

Cardio-metabolic profile

Weight loss

Obese adolescents

\begin{abstract}
S U M M A R Y
Background \& aims: In vivo and in vitro evidence suggests that antioxidant vitamins and carotenoids may be key factors in the treatment and prevention of obesity and obesity-associated disorders. Hence, the objective of the present study was to determine the relationship between plasma lipid-soluble antioxidant vitamin and carotenoid levels and adiposity and cardio-metabolic risk markers in overweight and obese adolescents participating in a multidisciplinary weight loss programme.

Methods: A therapeutic programme was conducted with 103 adolescents aged 12-17 years old and diagnosed with overweight or obesity. Plasma concentrations of $\alpha$-tocopherol, retinol, $\beta$-carotene and lycopene, anthropometric indicators of general and central adiposity, blood pressure and biochemical parameters were analysed at baseline and at 2 and 6 months of treatment.

Results: Lipid-corrected retinol $(P<0.05), \beta$-carotene $(P=0.001)$ and $\alpha$-tocopherol $(P<0.001)$ plasma levels increased significantly, whereas lipid-corrected lycopene levels remained unaltered during the treatment. Anthropometric indicators of adiposity $(P<0.001)$, blood pressure $(P<0.01)$ and biochemical parameters $(P<0.05)$ decreased significantly, whereas fat free mass increased significantly $(P<0.001)$. These clinical and biochemical improvements were related to changes in plasma lipid-corrected antioxidant vitamin and carotenoid levels. The adolescents who experienced the greatest weight loss also showed the largest decrease in anthropometric indicators of adiposity and biochemical parameters and the highest increase in fat free mass. Weight loss in these adolescents was related to an increase in plasma levels of lipid-corrected $\alpha$-tocopherol $(P=0.001), \beta$-carotene $(P=0.034)$ and lycopene $(P=0.019)$.
\end{abstract}

Abbreviations: ApoA1, apolipoprotein A1; ApoB, apolipoprotein B; BMI, body mass index; CRP, C-reactive protein; CVD, cardiovascular diseases; DBP, diastolic blood

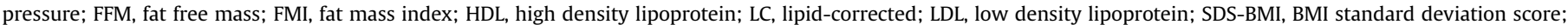
SBP, systolic blood pressure; TAG, triacylglycerols; UHPLC, Ultra High Performance Liquid Chromatography.

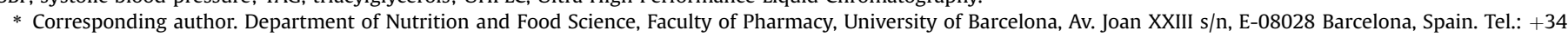
934024512.

E-mail address: mclopez@ub.edu (M.C. López-Sabater). 
Conclusions: Plasma lipid-soluble antioxidant vitamin and carotenoid levels are associated with reduced adiposity, greater weight loss and an improved cardio-metabolic profile in overweight and obese adolescents.

๑ 2015 Elsevier Ltd and European Society for Clinical Nutrition and Metabolism. All rights reserved.

\section{Introduction}

The prevalence of obesity has increased in recent decades and this disorder is now considered a 21st century epidemic. It is the most common nutritional issue among children and adolescents in developed countries, but has also reached alarming values in developing countries [1].

Obesity is an important risk factor of cardiovascular diseases (CVD) and is strongly related to other cardiovascular risk factors such as hypertension, diabetes, dyslipidemia and inflammation [2], therefore onset of obesity is of particular concern in children and adolescents $[3,4]$. It has been found that similar to obese adults, obese children present a higher degree of oxidative stress than their normal weight counterparts [5]. Moreover, obesity is linked to decreased plasma antioxidant vitamin levels and antioxidant capacity [6]. Thus, the scientific evidence suggests that antioxidant vitamins and carotenoids may be key factors in the treatment and prevention of obesity and obesity-associated disorders.

Recent studies have indicated that vitamin A [7] and $\beta$-carotene [8] are important regulators of body fat reserves. As an example, retinoic acid derived from vitamin $A$ and $\beta$-carotene is involved in the expression of lipogenic transcription factors [7,8]. Furthermore, it has been observed that vitamin A and carotenoids present antiinflammatory properties [9-11] and have an antioxidant action [10-12]. Within the carotenoids, lycopene has the highest antioxidant capacity compared to $\alpha$-tocopherol and $\beta$-carotene [13]. Numerous epidemiological studies have shown a significant inverse association between plasma or tissue lycopene levels and the incidence of CVD or CVD risk factors (atherosclerosis, hypertension, diabetes, metabolic syndrome, inflammation and oxidative stress) [12]. Also, it has been suggested that lycopene can prevent inflammation [11] by decreasing transcription factor activation and secretion of inflammatory markers in adipose tissue [9].

Vitamin E is another lipid-soluble vitamin that presents a high antioxidant capacity $[13,14]$. Recently, it was found that vitamin $\mathrm{E}$ is involved in the expression of genes associated with glucose and lipid metabolism $[15,16]$. In addition, some authors have observed a lower incidence of chronic disease and cardiovascular events when dietary intake of vitamin $\mathrm{E}$ is increased [14].

The study of changes in anthropometric and metabolic parameters and plasma antioxidant levels in obese children is useful in order to determine their associations and establish dietary regimes aimed at reducing the prevalence of paediatric obesity and associated pathologies. Nonetheless, to our knowledge, few studies have focussed in this issue. Hence, the objective of the present study was to determine the relationship between plasma levels of $\alpha$-tocopherol, retinol, $\beta$-carotene and lycopene and adiposity and cardio-metabolic risk markers in overweight and obese adolescents participating in a multidisciplinary weight loss programme.

\section{Materials and methods}

\subsection{Ethics statement}

This study was conducted in accordance with the ethical rules of the Helsinki Declaration (Hong Kong revision, September 1989,
Edinburgh revision 2000 and Korea revision 2008), the European Economic Community (EEC) Good Clinical Practice guidelines (document 111/3976/88 of July 1990) and current Spanish law, which regulates clinical research on humans (Royal Decree 561/ 1993 regarding clinical trials). Written informed consent was obtained from all adolescents and their parents, and the study was approved by the local ethics committees. Data obtained during the intervention was confidential and restricted to the participating investigators.

\subsection{Participants and study design}

The study sample used in the present analysis comprised 103 adolescents aged 12-17 years old and diagnosed with overweight and obesity at four hospitals located in different Spanish cities (Granada, Madrid, Pamplona and Zaragoza). The inclusion criteria were as follows: to be overweight or obese as defined by International Obesity Task Force age- and sex-specific body mass index (BMI) values [17], to be Spanish or to have been educated in Spain, and to be free of any other diagnosed disease. Adolescents receiving pharmacological treatment or diagnosed with anorexia, bulimia or any other eating disorder except binge eating disorder, were excluded. All selected adolescents were treated as part of the EVASYON Study (Development, implementation and evaluation of the efficacy of a therapeutic programme for adolescents with overweight and obesity: comprehensive education on nutrition and physical activity) [18].

The EVASYON project was an intervention study in a cohort of overweight and obese adolescents. It comprised a long-term (approximately 13 months) multidisciplinary treatment programme based on a calorie-restricted diet (10-40\%), increased physical activity (at least $60 \mathrm{~min} /$ day, 5 days a week), psychological therapy and nutritional education. The maximum energy intake was $1800 \mathrm{kcal} /$ day for females and $2200 \mathrm{kcal} /$ day for males. Macronutrient distribution was 50\% of energy from carbohydrates, $30 \%$ from fat and $20 \%$ from proteins. The adolescents were treated in groups of a maximum of 10 subjects and each group had 20 visits during the intervention. The treatment comprehended two stages, an intensive intervention phase (1st to 9th visits) with weekly checks during the first 2 months, and an extensive intervention phase (10th to 20th visits) where adolescents were monitored monthly until the end of programme. The complete and detailed methodology of the EVASYON Study has been described elsewhere [18].

\subsection{Dietary intake and physical condition}

Dietary intake was assessed by applying 72-h dietary record and a semi-quantitative food-frequency questionnaire, previously validated. Data of food intake by 72 -h dietary record were transformed into food volume/weight (in $\mathrm{mL}$ or $\mathrm{g}$ ). The nutrient consumption was determined using the latest available information in food-composition tables from Spain. Vitamins and carotenoids were estimated from the intake of respective food sources.

To evaluate the physical activity, several tests and questionnaire were used, such as Physical Activity Questionnaire for Adolescents 
(PAQ-A), Course navette or $20-\mathrm{m}$ Shuttle run test, Handgrip strength, $4 \times 10$-m shuttle-run, among others. The complete and detailed methodology has been described elsewhere [18].

\subsection{Anthropometry, pubertal development and resting blood pressure}

Body weight $(\mathrm{kg})$ was measured without shoes and with light clothing to the nearest $0.05 \mathrm{~kg}$ using a standard beam balance. Triceps, biceps, subscapular, suprailiac, thigh and calf skin-fold thicknesses were measured on the left side of the body to the nearest $0.2 \mathrm{~mm}$ using a Holtain skin-fold calliper. All the anthropometric variables were measured consecutively in triplicate and averaged. For all the anthropometric measurements, intra-observer reliability was $>95 \%$ and inter-observer reliability was $>90 \%$.

Pubertal development was assessed in accordance with the 5stage system established by Tanner [19]. Each stage describes pubic hair and breast development in girls and pubic hair and genital development in boys.

Blood pressure was measured using a validated digital automatic blood pressure monitor (Omron M6, Omron Health Care Co., Ltd., Kyoto, Japan) in accordance with the International Protocol of the European Society of Hypertension [20].

\subsection{Biochemical and metabolic analysis}

Blood was collected by venipuncture after an overnight fast. It was then centrifuged and aliquots of plasma or serum were stored at $-80{ }^{\circ} \mathrm{C}$ until analysis.

Total cholesterol, high density lipoprotein (HDL) cholesterol, triacylglycerols (TAG) and glucose were analysed using an Olympus AU2700 biochemical autoanalyser (Olympus, Melville, NY, USA). The coefficients of variance obtained were $2 \%$ for total cholesterol, $2 \%$ for HDL cholesterol and 3\% for TAG. Very-low-density lipoprotein (VLDL) cholesterol and low density lipoprotein (LDL) cholesterol were calculated from existing values for cholesterol, HDL cholesterol and triglycerides [21]. Apolipoprotein B (apoB) and A1 (apoA1), insulin and C-reactive protein (CRP) were analysed using the methodology described in full detail elsewhere [18].

\subsection{Determination of plasma antioxidant vitamins and carotenoids}

Plasma levels of $\alpha$-tocopherol, retinol, $\beta$-carotene and lycopene were determined at three different periods: before starting treatment, at 2 months and at 6 months of intervention. Analyses were carried out by Ultra High Performance Liquid Chromatography (UHPLC). Individual stock standard solutions were prepared for $\alpha$ tocopherol, $\alpha$-tocopherol acetate, retinol and retinyl acetate in ethanol, while $\beta$-carotene and lycopene standard solutions were prepared in dichloromethane:methanol (2:1). Concentration ranges for calibration were $5-150 \mu \mathrm{g} / \mathrm{mL}$ ( $\alpha$-tocopherol) and $0.1-5 \mu \mathrm{g} / \mathrm{mL}$ (retinol, $\beta$-carotene, lycopene). Sample analysis was performed as follows: $300 \mu \mathrm{L}$ of previously vortexed plasma was de-proteinated with $500 \mu \mathrm{L}$ of internal standard mixture $(0.6 \mu \mathrm{g} / \mathrm{mL}$ retinyl acetate and $17 \mu \mathrm{g} / \mathrm{mL} \alpha$-tocopherol acetate in ethanol), vortexed for $1 \mathrm{~min}$ and extracted by centrifugation $(4000 \mathrm{rpm}$, $5 \mathrm{~min}, 21-22^{\circ} \mathrm{C}$ ) twice with $1 \mathrm{~mL}$ of hexane. The organic phase obtained was filtered using Acrodisc $13 \mathrm{~mm}$ Syringe Filter equipped with $0.2 \mu \mathrm{m}$ GHP membranes, and was then evaporated to dryness under nitrogen atmosphere at $35{ }^{\circ} \mathrm{C}$. The residues were reconstituted to $50 \mu \mathrm{L}$ with a solution of dichloromethane:methanol (2:1) and vortexed for $15 \mathrm{~s}$. Chromatographic determination was performed using an Acquity Ultra Performance Liquid Chromatographic System (UPLC) (Waters, Milford, MA, USA) equipped with a binary solvent delivery module and a 2996 Photodiode Array (PDA) detector. An Acquity UPLC BEH C18 column $(2.1 \mathrm{~mm}$ i.d. $\times 50 \mathrm{~mm}$, $1.7 \mu \mathrm{m}$ particle size) (Waters, Milford, MA, USA) and an Acquity UPLC BEH C18 Van Guard Pre-column $(2.1 \mathrm{~mm}$ i.d. $\times 5 \mathrm{~mm}, 1.7 \mu \mathrm{m}$ particle size) (Waters, Milford, MA, USA) were used. Column and autosampler temperatures were $30{ }^{\circ} \mathrm{C}$ and $10{ }^{\circ} \mathrm{C}$, respectively. Methanol was used as mobile phase at a flow rate of $0.6 \mathrm{~mL} / \mathrm{min}$. Injection volume was $3 \mu \mathrm{L}$ and total run time $3 \mathrm{~min}$. The wavelengths selected were 325, 292 and $450 \mathrm{~nm}$ for retinol, tocopherol and carotenoid analysis, respectively. The validity of the UHPLC method was assessed by including serum calibration standards and bi-level serum controls (Chromsystems, Munich, Germany). Method validation results are presented in Table 1.

\subsection{Statistical analysis}

Results are presented as means \pm standard deviation (SD) or standard error of the mean (SEM). SPSS 20.0 (SPSS Inc, Chicago, IL, USA) was used for statistical analyses. Changes in clinical or biochemical parameters and plasma lipid-soluble antioxidant vitamin and carotenoid levels were analysed by general linear models using Bonferroni post hoc correction. To evaluate the association between changes in antioxidant vitamins and carotenoids and anthropometric indicators of adiposity, blood pressure and biochemical parameters at 2 and 6 months of intervention, linear regression models were applied, adjusted for age, sex, body mass index standard deviation score (SDS-BMI) and Tanner stages at baseline, changes in intake of energy and corresponding vitamins or carotenoids at 6 months respect to baseline, and degree of physical activity. General linear models were also carried out to examine the differences between changes in clinical and biochemical parameters and changes in plasma vitamin and carotenoid levels at 6 months of intervention in the different weight loss groups, controlling for potential confounding factors (sex, age, SDS-BMI, Tanner stage and the corresponding variable at baseline, changes in intake of energy and corresponding vitamins or carotenoids at 6 months, and degree of physical activity). To determine whether changes in parameters studied were significant in each group of weight loss, estimated marginal means were used. For all analyses, two-sided significance was determined at a $P<0.05$.

\section{Results}

The clinical and biochemical characteristics, physical condition and dietary intake of adolescents, at baseline and at 2 and 6 months of treatment, are given in Table 2. Participants' mean age and baseline body mass index (BMI) were $14.09 \pm 1.21$ years old and $31.4 \pm 0.49 \mathrm{~kg} / \mathrm{m}^{2}$, respectively; $46 \%$ were males and $54 \%$ females. It was found that weight and anthropometric indicators of total adiposity [BMI, SDS-BMI, body fat and fat mass index (FMI)] and central adiposity (waist circumference) decreased significantly during the 6 months of intervention $(P<0.001)$, whereas the percentage of fat free mass (FFM) increased $(P<0.001)$. Systolic (SBP) and diastolic blood pressure (DBP) improved after 2 months of treatment $(P=0.002$ and $<0.001$, respectively), subsequently remaining unchanged until the end of treatment. Most of the biochemical parameters (glucose, insulin, cholesterol, HDL cholesterol, LDL cholesterol, apoA1, apoB and CRP) decreased during the intensive intervention phase $(P<0.05)$. However, the TAG and apolipoprotein B/apolipoprotein $A 1$ (apoB/apoA1) ratio only changed at the end of the programme $(P=0.001)$, showing values lower than those measured at baseline and 2 months of intensive treatment. During the extensive intervention phase, some of the parameters which had decreased during the intensive period, such as cholesterol, HDL cholesterol and apoA1, became higher with 
Table 1

Parameters of UHPLC method validation for lipid-soluble vitamins and carotenoids.

\begin{tabular}{|c|c|c|c|c|c|c|c|c|c|}
\hline \multirow[t]{2}{*}{ Analytes } & \multicolumn{2}{|l|}{ Repeatability $(\mathrm{n}=10)$} & \multicolumn{2}{|c|}{ Reproducibility $(\mathrm{n}=20)$} & \multicolumn{2}{|l|}{ Linearity } & \multirow[t]{2}{*}{ LOD (ng/mL) } & \multirow[t]{2}{*}{$\mathrm{LOQ}(\mathrm{ng} / \mathrm{mL})$} & \multirow[t]{2}{*}{ Recovery (\%) } \\
\hline & Means $\pm \mathrm{SD}(\mu \mathrm{g} / \mathrm{mL})$ & $\mathrm{CV}(\%)$ & Means $\pm \mathrm{SD}(\mu \mathrm{g} / \mathrm{mL})$ & $\mathrm{CV}(\%)$ & Equation & $r^{2}$ & & & \\
\hline$\alpha$-Tocopherol & $18.87 \pm 0.20$ & 1.04 & $18.98 \pm 0.36$ & 1.89 & $\mathrm{y}=0.0196 \mathrm{x}+0.0166$ & 0.9999 & 29 & 99 & 103 \\
\hline Retinol & $0.62 \pm 0.01$ & 1.89 & $0.61 \pm 0.03$ & 4.28 & $\mathrm{y}=0.2559 \mathrm{x}-0.0105$ & 1 & 1.6 & 5.2 & 97 \\
\hline Lycopene & $0.15 \pm 0.01$ & 4.22 & $0.15 \pm 0.01$ & 6.96 & $y=0.4508 x+0.006$ & 0.9998 & 2.2 & 7.3 & 92 \\
\hline$\beta$-Carotene & $0.09 \pm 0.00$ & 4.62 & $0.08 \pm 0.01$ & 6.12 & $\mathrm{y}=0.5581 \mathrm{x}+0.007$ & 0.9999 & 1.8 & 6.1 & 91 \\
\hline
\end{tabular}

$\mathrm{CV}$, coefficient of variation; LOD, limit of detection; LOQ limit of quantification.

respect to 2 months $(P<0.001)$, but did not return to the baseline values. Regarding to physical condition, it was observed that agility and cardiorespiratory endurance improved from 2 months $(P<0.001)$, whilst handgrip strength increased significantly at the end of intervention $(P<0.001)$. On the other hand, the intake of energy, carbohydrates, proteins, lipids, vitamin A and vitamin $\mathrm{E}$ decreased $(P<0.001)$, whereas $\beta$-carotene intake enhanced $(P=0.014)$ and lycopene tended to increase $(P=0.064)$.

Changes in plasma $\alpha$-tocopherol, retinol, lycopene and $\beta$-carotene levels during treatment are presented in Fig. 1. Values are expressed as concentration, and also applying a lipid correction [6] by dividing the concentration by the sum of cholesterol and TAG. It was observed that lipid-corrected (LC) retinol increased significantly at 2 months of treatment $(P<0.05)$, whereas LC $\beta$-carotene $(P=0.001)$ and LC $\alpha$-tocopherol $(P<0.001)$ were significantly higher in the final stage of the treatment. LC lycopene levels did not change during the intervention.

Table 3 shows the associations between the changes in plasma antioxidant vitamin and carotenoid levels and the changes in several clinical and biochemical parameters at 2 and 6 months, in relation to baseline values. Since LC lycopene remained unaltered during the treatment, its correlations with other parameters have not been explored. As shown in Fig. 1, the changes LC retinol levels were significant at 2 months of treatment. Thus, the increase in LC retinol was associated with a reduction in cholesterol and TAG $(P<0.001)$.

The changes in LC $\alpha$-tocopherol and LC $\beta$-carotene levels were significant at 6 months of intervention (see Fig. 1). Hence, the increase in LC $\alpha$-tocopherol was inversely related to weight $(P<0.01)$, BMI $(P<0.01)$, SDS-BMI $(P<0.01)$, body fat $(P<0.01)$, FMI

Table 2

Characteristics of study population at baseline and during the weight loss treatment.

\begin{tabular}{|c|c|c|c|c|c|}
\hline Characteristics & $\mathrm{N}$ & Baseline & 2 months & 6 months & $P$ \\
\hline \multicolumn{6}{|l|}{ Clinical parameters } \\
\hline Weight (kg) & 106 & $85.7 \pm 1.66^{\mathrm{A}}$ & $81.5 \pm 1.57^{\mathrm{B}}$ & $80.2 \pm 1.58^{C}$ & $<0.001$ \\
\hline BMI $\left(\mathrm{kg} / \mathrm{m}^{2}\right)$ & 106 & $31.4 \pm 0.49^{\mathrm{A}}$ & $29.7 \pm 0.47^{\mathrm{B}}$ & $28.8 \pm 0.49^{C}$ & $<0.001$ \\
\hline SDS-BMI & 106 & $2.80 \pm 0.05^{\mathrm{A}}$ & $2.55 \pm 0.06^{\mathrm{B}}$ & $2.35 \pm 0.07^{C}$ & $<0.001$ \\
\hline Waist circumference $(\mathrm{cm})$ & 97 & $99.0 \pm 1.24^{\mathrm{A}}$ & $95.8 \pm 1.16^{\mathrm{B}}$ & $90.8 \pm 1.17^{C}$ & $<0.001$ \\
\hline Body fat $(\%)$ & 93 & $35.8 \pm 0.47^{\mathrm{A}}$ & $34.3 \pm 0.50^{\mathrm{B}}$ & $33.2 \pm 0.60^{C}$ & $<0.001$ \\
\hline Body fat (kg) & 92 & $30.8 \pm 0.80^{\mathrm{A}}$ & $28.1 \pm 0.76^{\mathrm{B}}$ & $26.8 \pm 0.82^{C}$ & $<0.001$ \\
\hline FMI $\left(\mathrm{kg} / \mathrm{m}^{2}\right)$ & 90 & $11.2 \pm 0.28^{\mathrm{A}}$ & $10.2 \pm 0.28^{\mathrm{B}}$ & $9.6 \pm 0.30^{C}$ & $<0.001$ \\
\hline FFM $(\%)$ & 93 & $64.2 \pm 0.47^{\mathrm{A}}$ & $65.7 \pm 0.50^{\mathrm{B}}$ & $66.8 \pm 0.60^{C}$ & $<0.001$ \\
\hline Systolic blood pressure (mm Hg) & 80 & $123.4 \pm 1.60^{\mathrm{A}}$ & $118.7 \pm 1.45^{\mathrm{B}}$ & $118.0 \pm 1.45^{\mathrm{B}}$ & 0.002 \\
\hline Diastolic blood pressure (mm Hg) & 80 & $72.6 \pm 1.29^{\mathrm{A}}$ & $67.4 \pm 1.23^{\mathrm{B}}$ & $67.1 \pm 1.04^{\mathrm{B}}$ & $<0.001$ \\
\hline \multicolumn{6}{|l|}{ Biochemical parameters } \\
\hline Glucose $(\mathrm{mmol} / \mathrm{L})$ & 97 & $4.63 \pm 0.04^{\mathrm{A}}$ & $4.51 \pm 0.05^{\mathrm{B}}$ & $4.54 \pm 0.05^{\mathrm{A}, \mathrm{B}}$ & 0.012 \\
\hline Insulin $(\mu \mathrm{UI} / \mathrm{mL})$ & 20 & $18.8 \pm 3.00^{\mathrm{A}}$ & $14.5 \pm 1.46^{\mathrm{B}}$ & $14.8 \pm 1.58^{\mathrm{B}}$ & 0.047 \\
\hline Cholesterol (mmol/L) & 106 & $4.01 \pm 0.06^{\mathrm{A}}$ & $3.67 \pm 0.07^{\mathrm{B}}$ & $3.77 \pm 0.07^{C}$ & $<0.001$ \\
\hline HDL-cholesterol (mmol/L) & 104 & $1.15 \pm 0.03^{\mathrm{A}}$ & $1.05 \pm 0.03^{\mathrm{B}}$ & $1.14 \pm 0.03^{C}$ & $<0.001$ \\
\hline LDL-cholesterol (mmol/L) & 104 & $2.34 \pm 0.06^{\mathrm{A}}$ & $2.14 \pm 0.06^{\mathrm{B}}$ & $2.17 \pm 0.06^{\mathrm{B}}$ & $<0.001$ \\
\hline Triacylglycerol (mmol/L) & 106 & $1.01 \pm 0.05^{\mathrm{A}}$ & $0.91 \pm 0.05^{\mathrm{A}}$ & $0.86 \pm 0.04^{\mathrm{B}}$ & 0.001 \\
\hline Apolipoprotein A1 (mg/dL) & 73 & $117.14 \pm 2.16^{\mathrm{A}}$ & $106.64 \pm 1.86^{\mathrm{B}}$ & $112.79 \pm 2.03^{C}$ & $<0.001$ \\
\hline Apolipoprotein B (mg/dL) & 73 & $69.93 \pm 2.06^{\mathrm{A}}$ & $65.32 \pm 2.04^{\mathrm{B}}$ & $65.09 \pm 2.32^{\mathrm{B}}$ & $<0.001$ \\
\hline ApoB/apoA1 ratio & 73 & $0.62 \pm 0.19^{\mathrm{A}, \mathrm{B}}$ & $0.63 \pm 0.18^{\mathrm{A}}$ & $0.59 \pm 0.19^{\mathrm{B}}$ & 0.002 \\
\hline C-reactive protein $(\mathrm{mg} / \mathrm{L})$ & 58 & $3.26 \pm 0.43^{\mathrm{A}}$ & $2.12 \pm 0.23^{\mathrm{B}}$ & $2.12 \pm 0.20^{\mathrm{B}}$ & 0.001 \\
\hline \multicolumn{6}{|l|}{ Physical condition } \\
\hline Hand grip strength $(\mathrm{kg})$ & 107 & $29.12 \pm 7.78^{\mathrm{A}}$ & $29.82 \pm 8.10^{\mathrm{A}}$ & $30.51 \pm 8.08^{\mathrm{B}}$ & $<0.001$ \\
\hline Agility (seconds) & 106 & $13.62 \pm 1.53^{\mathrm{A}}$ & $13.03 \pm 1.50^{\mathrm{B}}$ & $13.01 \pm 1.28^{\mathrm{B}}$ & $<0.001$ \\
\hline Cardiorespiratory endurance (periods) & 98 & $3.07 \pm 1.52^{\mathrm{A}}$ & $3.56 \pm 1.82^{\mathrm{B}}$ & $3.77 \pm 1.80^{\mathrm{B}}$ & $<0.001$ \\
\hline \multicolumn{6}{|l|}{ Dietary intake } \\
\hline Energy $(\mathrm{kcal} / \mathrm{d})$ & 113 & $3336.87 \pm 1613.99^{A}$ & - & $2202.02 \pm 625.56^{\mathrm{B}}$ & $<0.001$ \\
\hline Carbohydrates (g/d) & 113 & $362.9 \pm 181.09^{\mathrm{A}}$ & - & $249.38 \pm 74.33^{\mathrm{B}}$ & $<0.001$ \\
\hline Proteins $(\mathrm{g} / \mathrm{d})$ & 113 & $130.81 \pm 59.27^{\mathrm{A}}$ & - & $108.55 \pm 30.45^{\mathrm{B}}$ & $<0.001$ \\
\hline Lipids (g/d) & 113 & $151.04 \pm 84.42^{\mathrm{A}}$ & - & $85.30 \pm 34.83^{B}$ & $<0.001$ \\
\hline Total fibre $(\mathrm{g} / \mathrm{d})$ & 113 & $27.05 \pm 13.01^{\mathrm{A}}$ & - & $26.26 \pm 9.91^{\mathrm{A}}$ & 0.553 \\
\hline Vitamin $A(\mu \mathrm{g} / \mathrm{d})^{\mathrm{a}}$ & 90 & $486.26 \pm 601.23^{\mathrm{A}}$ & - & $197.15 \pm 314.49^{\mathrm{B}}$ & $<0.001$ \\
\hline Vitamin E (mg/d $)^{a}$ & 100 & $11.44 \pm 10.81^{\mathrm{A}}$ & - & $6.03 \pm 4.53^{\mathrm{B}}$ & $<0.001$ \\
\hline$\beta$-Carotene $(\mu \mathrm{g} / \mathrm{d})^{\mathrm{a}}$ & 108 & $3724.94 \pm 4602.29^{\mathrm{A}}$ & - & $4997.34 \pm 3882.13^{\text {B }}$ & 0.014 \\
\hline Lycopene $(\mu \mathrm{g} / \mathrm{d})^{\mathrm{a}}$ & 107 & $119.29 \pm 168.66^{\mathrm{A}}$ & - & $152.86 \pm 160.73^{A}$ & 0.064 \\
\hline
\end{tabular}

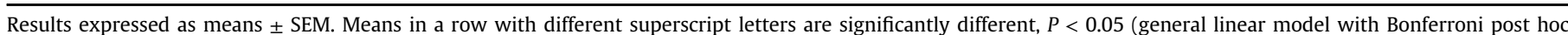

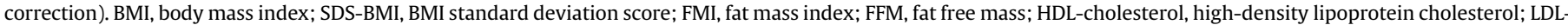
cholesterol, low-density lipoprotein cholesterol; ApoB/apoA1 ratio, apolipoprotein B/apolipoprotein A1 ratio.

a Determined from intake of dietary sources. 


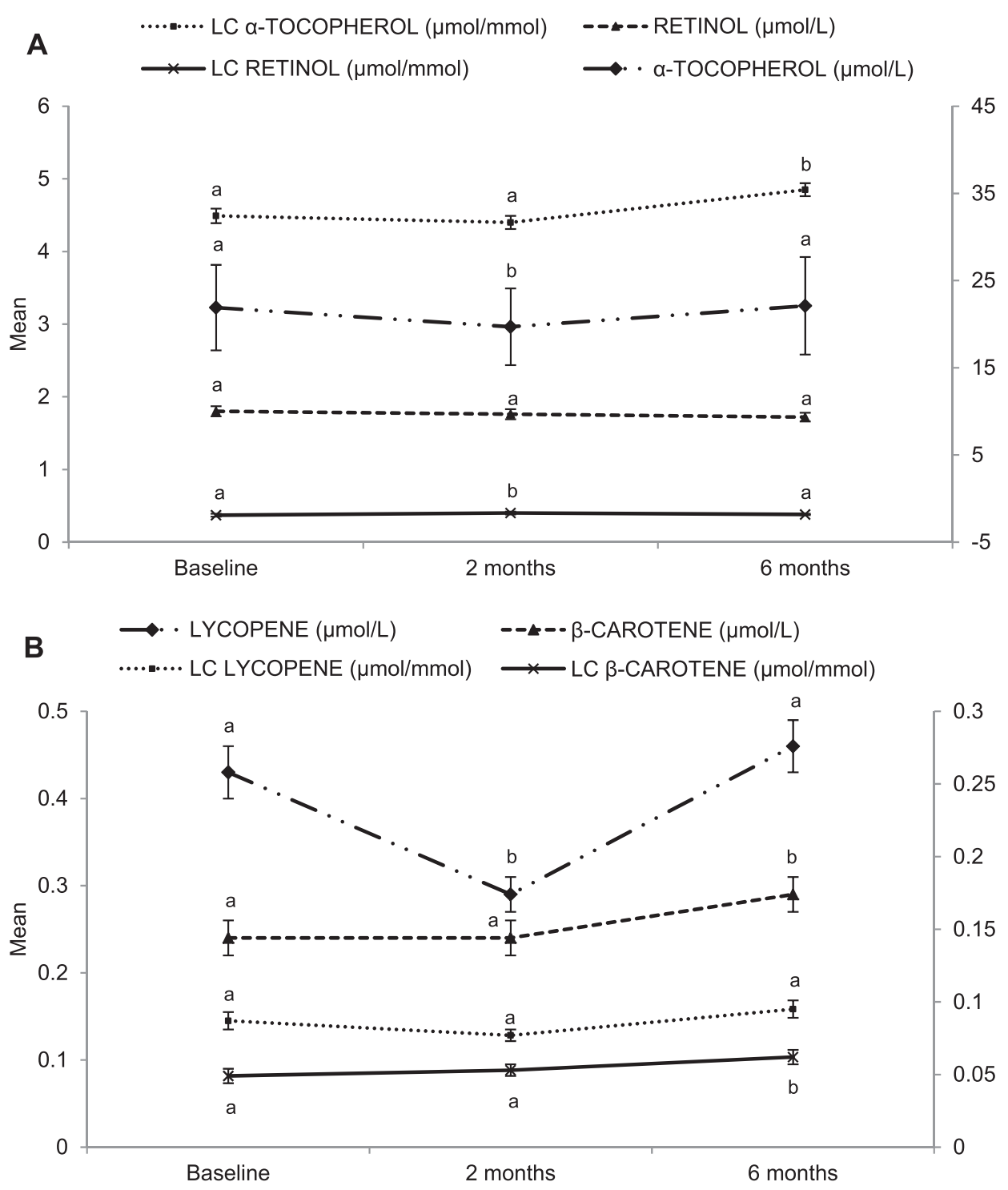

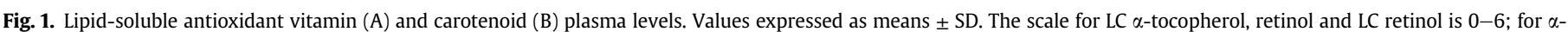

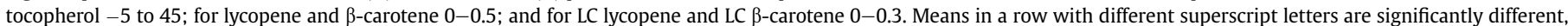

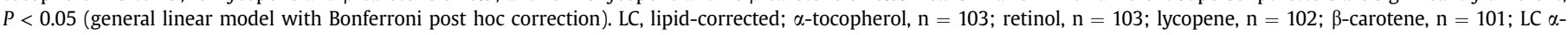
tocopherol, $\mathrm{n}=85$; $\mathrm{LC}$ retinol, $\mathrm{n}=85$; LC lycopene, $\mathrm{n}=84$; LC $\beta$-carotene, $\mathrm{n}=83$.

$(P<0.01)$, cholesterol $(P<0.001)$, LDL cholesterol $(P<0.05)$ and TAG $(P<0.001)$. Conversely, the relationship observed between LC $\alpha$-tocopherol and FFM was positive $(P<0.01)$. LC $\beta$-carotene concentration showed a significant and negative association with insulin $(P<0.01)$ and HDL cholesterol $(P<0.001)$.

In our study, the degree of weight loss in adolescents during the programme proposed was defined as the decrease in SDS-BMI. Changes in clinical and biochemical parameters, antioxidant vitamins and carotenoids, defined as a reduction in SDS-BMI at 6 months follow up, are given in Fig. 2. Adolescents were divided into three groups according to changes in SDS-BMI between baseline and 6 months of intervention. The SDS-BMI decrease $>0.5$ group showed the largest decrease in anthropometric indicators of adiposity $(P<0.001)$ and biochemical parameters $(P<0.05)$, whereas the SDS-BMI decrease $<0.25$ group presented the lowest reduction, or the opposite behaviour (Fig. 2A and B, respectively). Conversely, the highest increase in FFM was observed in the SDS$B M I$ decrease $>0.5$ group and the lowest in the SDS-BMI decrease $<0.25$ group $(P<0.001)$. No differences were found between the weight loss groups in SBP, DBP, glucose, insulin, HDL cholesterol, CRP, apoA1 and the apoB/apoA1 ratio.

On the other hand, by comparing the baseline values with those obtained at 6 months of treatment in the same group of weight loss, it was found that the clinical and biochemical parameters, excepting insulin and HDL cholesterol, changed significantly in the SDS-BMI decrease $>0.5$ group $(P<0.05)$. Should be noted that the indicators of general adiposity decreased and the FFM increased significantly even in the adolescents that had a lower weigh loss (SDS-BMI decrease $<0.25)(P<0.05)$.

In relation to antioxidant vitamin and carotenoid levels at 6 months (Fig. 2C), it was observed that the changes in LC retinol were independent to degree of weight loss, because there were no differences between groups or in the same group. When comparing the vitamin levels at 6 months with baseline values for each weight loss group, it was observed that LC $\beta$-carotene $(P=0.034)$ and LC $\alpha$ tocopherol $(P=0.001)$ increased significantly in the adolescents 
Table 3

Association between changes in plasma antioxidant vitamin and carotenoid levels and clinical and biochemical parameters at 2 and 6 months of treatment.

\begin{tabular}{|c|c|c|c|c|c|c|}
\hline \multirow[t]{2}{*}{ Parameters $^{\mathrm{a}}$} & \multicolumn{3}{|l|}{2 months } & \multicolumn{3}{|l|}{6 months } \\
\hline & $\alpha$-Tocopherol ${ }^{\mathrm{a}, \mathrm{b}}$ & Retinol $^{\mathrm{a}, \mathrm{b}}$ & $\beta$-Carotene $e^{\mathrm{a}, \mathrm{b}}$ & $\alpha$-Tocopherol ${ }^{\mathrm{a}, \mathrm{b}}$ & Retinol $^{\mathrm{a}, \mathrm{b}}$ & $\beta$-Carotene $\mathrm{a}^{\mathrm{a}, \mathrm{b}}$ \\
\hline Weight (kg) & -0.162 & -0.061 & 0.174 & $-0.347^{* *}$ & -0.146 & -0.039 \\
\hline BMI $\left(\mathrm{kg} / \mathrm{m}^{2}\right)$ & -0.193 & -0.154 & 0.183 & $-0.380^{* *}$ & -0.174 & -0.088 \\
\hline SDS-BMI & -0.153 & -0.103 & 0.161 & $-0.398^{* *}$ & -0.141 & -0.112 \\
\hline $\mathrm{WC}(\mathrm{cm})$ & 0.243 & 0.107 & 0.084 & -0.164 & 0.064 & 0.151 \\
\hline Body fat (\%) & -0.252 & 0.216 & -0.012 & $-0.444^{* *}$ & -0.162 & -0.243 \\
\hline Body fat (kg) & -0.302 & 0.133 & 0.147 & $-0.412^{* *}$ & -0.147 & -0.101 \\
\hline FMI $\left(\mathrm{kg} / \mathrm{m}^{2}\right)$ & -0.284 & 0.066 & 0.128 & $-0.427^{* *}$ & -0.174 & -0.151 \\
\hline FFM (\%) & 0.302 & -0.216 & 0.012 & $0.444^{* *}$ & 0.162 & 0.243 \\
\hline $\mathrm{SBP}(\mathrm{mm} \mathrm{Hg})$ & -0.104 & 0.081 & 0.030 & 0.019 & 0.217 & 0.019 \\
\hline $\mathrm{DBP}(\mathrm{mm} \mathrm{Hg})$ & 0.272 & -0.046 & -0.192 & 0.215 & 0.084 & 0.254 \\
\hline Glucose (mmol/L) & 0.132 & -0.238 & 0.049 & 0.179 & -0.194 & 0.056 \\
\hline Insulin $(\mu \mathrm{UI} / \mathrm{mL})$ & 0.069 & -0.025 & -0.523 & -0.199 & 0.219 & $-0.778^{* *}$ \\
\hline Cholesterol (mmol/L) & $-0.495^{* *}$ & $-0.404^{*}$ & 0.156 & $-0.482^{* * *}$ & $-0.541^{* *}$ & -0.233 \\
\hline $\mathrm{HDL}-\mathrm{C}(\mathrm{mmol} / \mathrm{L})$ & -0.220 & 0.119 & -0.288 & -0.225 & -0.188 & $-0.526^{* * *}$ \\
\hline LDL-C (mmol/L) & $-0.418^{*}$ & -0.266 & 0.244 & $-0.329^{*}$ & $-0.403^{*}$ & -0.066 \\
\hline $\mathrm{TAG}(\mathrm{mmol} / \mathrm{L})$ & $-0.368^{*}$ & $-0.587^{* * *}$ & -0.016 & $-0.505^{* * *}$ & $-0.520^{* *}$ & -0.084 \\
\hline ApoA1 (mg/dL) & -0.116 & 0.111 & 0.085 & -0.121 & -0.137 & -0.226 \\
\hline ApoB (mg/dL) & -0.344 & -0.269 & 0.281 & -0.167 & $-0.455^{*}$ & -0.140 \\
\hline ApoB/apoA1 & -0.152 & -0.213 & 0.176 & 0.122 & $-0.513^{*}$ & -0.058 \\
\hline $\mathrm{CRP}(\mathrm{mg} / \mathrm{L})$ & 0.318 & -0.235 & -0.071 & 0.129 & -0.003 & 0.133 \\
\hline
\end{tabular}

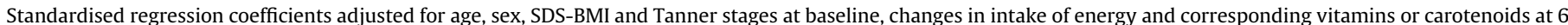
months, and degree of physical activity; ${ }^{*} P<0.05,{ }^{* *} P<0.01,{ }^{* * *} P<0.001$ (linear regression model).

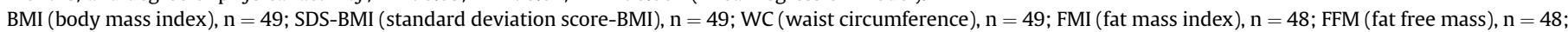

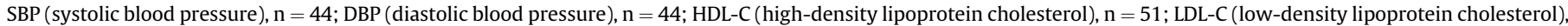

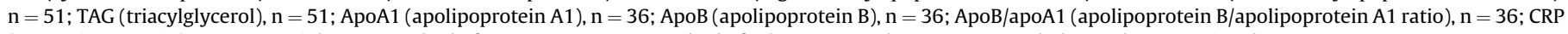
(C-reactive protein), $n=36$. Weight, $n=49$; body fat percentage, $n=48$; body fat $\mathrm{kg}, \mathrm{n}=48$; glucose, $\mathrm{n}=51$; cholesterol, $\mathrm{n}=51$; insulin, $\mathrm{n}=15$.

a Changes in parameters between the baseline and 2 or 6 months of treatment.

b Lipid-corrected values.

that experienced a decrease in SDS-BMI higher than 0.5, whereas LC lycopene improved in SDS-BMI decrease $0.25-0.5$ group $(P=0.019)$.

\section{Discussion}

Since plasma lipid-soluble vitamins and carotenoids are carried by lipoproteins [11,16] and given the relationship detected, in our study, between plasma lipids and changes in vitamin or carotenoid concentrations (data not shown), the effects of $\alpha$-tocopherol, retinol, $\beta$-carotene and lycopene on biochemical and clinical parameters were analysed using their lipid-corrected levels [6].

Previous studies have reported that obese children present higher lipid concentrations [3,6] and peroxidation [5] than their normal weight counterparts. Antioxidant vitamins and carotenoids reduce lipid peroxidation and enhance $L D L$ cholesterol resistance to oxidation $[11,12]$. In turn, there is evidence that whether adjusted and unadjusted for lipids, both $\beta$-carotene and $\alpha$-tocopherol levels are lower in obese children [6]. The negative association confirmed, in this research, between changes in lipid concentration and changes in LC $\alpha$-tocopherol, LC retinol and LC $\beta$-carotene suggests that the increase in plasma antioxidant vitamins and carotenoids may protect obese adolescents against oxidative stress.

In agreement with other studies, in which obese adults [23] and adolescents [24] were subjected to different dietary regimes, we found that HDL cholesterol decreased in the first stage of treatment. The subsequent recovery of this and apolipoprotein A1 (apoA1) was essential because they play an important role in removing the excess of cholesterol from tissues, consequently exerting an antiatherogenic effect $[2,22]$. Current studies have suggested that the apoB/apoA1 ratio predicts CVD risk better than any traditional cholesterol index, such as total cholesterol or LDL cholesterol [25]. Since in this study, the apoB/apoA1 ratio decreased in the last stage of intervention, a reduction in the participants' risk of CVD could be reached.
Recently, insulin resistance and hyperinsulinemia have emerged as major concerns in overweight and obese children [3], since both may lead to impaired glucose tolerance and type- 2 diabetes [26]. In addition to obesity itself, hyperinsulinemia and insulin resistance may play an important role as sources of oxidative stress [27] and they are related to reduced endogen and exogen antioxidants [6] in children and adolescents. In the present study, the decrease in plasma fasting insulin may be explained by the increase in $\beta$-carotene levels at 6 months of treatment, which is consistent with the results reported by other authors [6].

In relation to anthropometric indicators, we obtained interesting results for $\alpha$-tocopherol, since the increase in LC $\alpha$-tocopherol levels was associated to decrease in adiposity. These associations may be attributed to the strong antioxidant capacity of vitamin E $[13,14]$. The elevated protein oxidation and lipid peroxidation found in obese adolescents [5] may induce the production of inflammatory eicosanoids and cytokines [14], which suggests that improving $\alpha$-tocopherol concentrations may represent an useful anti-inflammatory approach. In addition, the role of vitamin $\mathrm{E}$ as regulator of enzymes and gene activity [16] has recently been discovered. Hence, $\boldsymbol{\alpha}$-tocopherol may modulate genes with an important function in endocrine signalling, specifically in glucose and lipid metabolism [16].

Regarding the degree of weight loss, in previous studies, only obese children and adolescents with a decrease in SDS-BMI > 0.5 have been observed to present an improved CVD risk factor profile and intima-media thickness [28], an early marker of atherosclerosis. However, we found a decrease in plasma proatherogenic lipids also in the SDS-BMI decrease $0.25-0.5$ group. In addition, BMI, body fat and FMI decreased even in the group with lower weight loss. This suggests that adiposity indicators, especially those of general adiposity and pro-atherogenic lipids, are more influenced by degree of weight loss than blood pressure, glucose, CRP and apolipoproteins. These findings could be useful when setting 
A a SDS-BMI decrease $<0.25$ घSDS-BMI decrease 0.25-0.5 $\approx$ SDS-BMI decrease $>0.5$

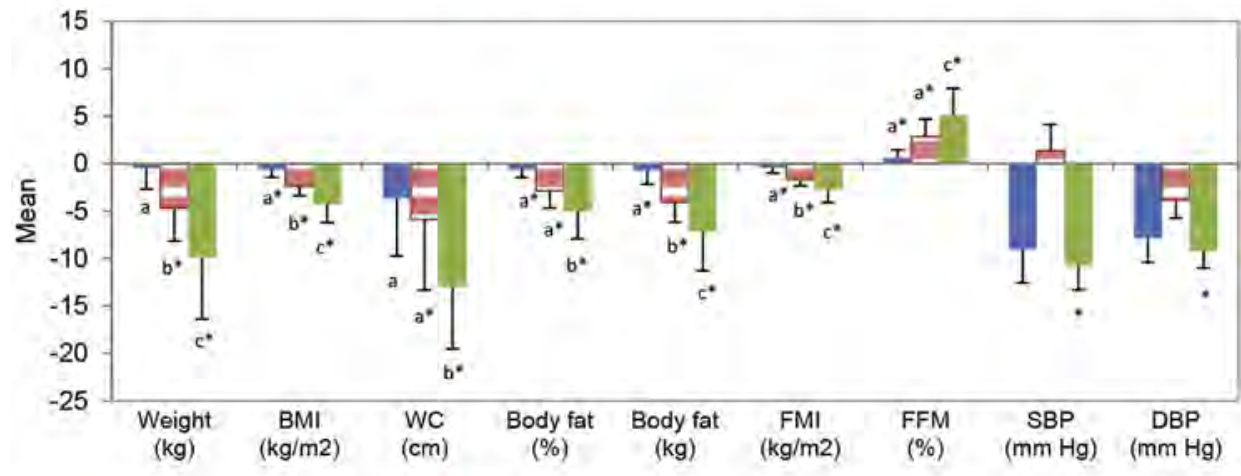

B $=$ SDS-BMI decrease $<0.25$ BSDS-BMI decrease 0.25-0.5 $=$ SDS-BMI decrease $>0.5$

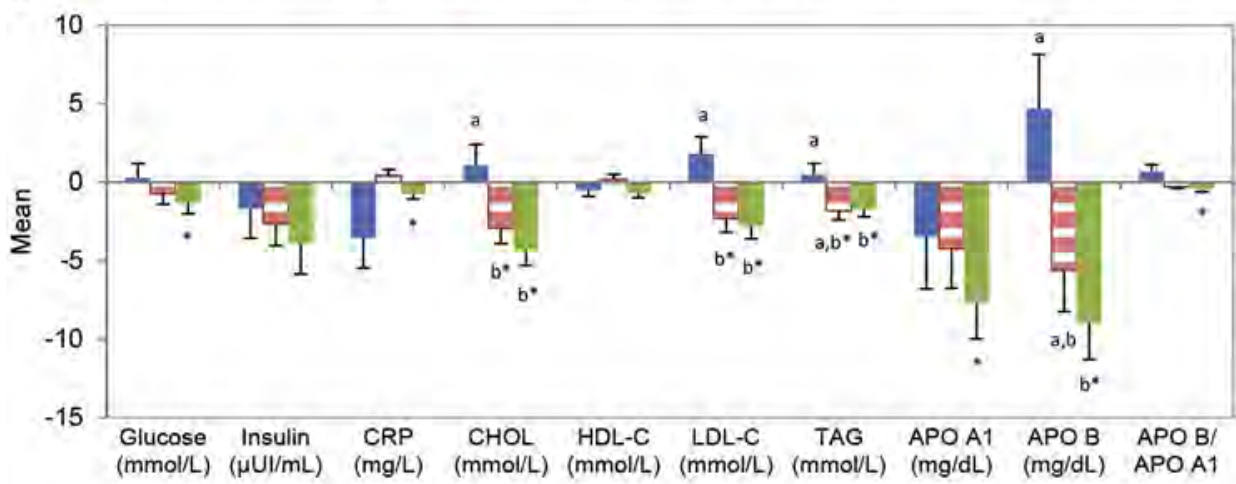

C $=$ SDS-BMI decrease $<0.25$ aSDS-BMI decrease 0.25-0.5 $\approx$ SDS-BMI decrease $>0.5$

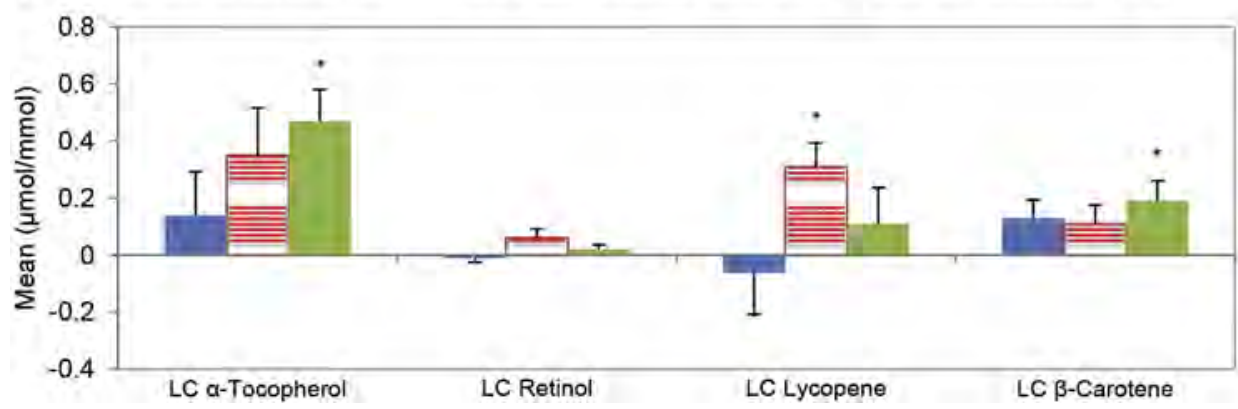

Fig. 2. Changes in clinical (A) and biochemical (B) parameters, lipid-soluble antioxidant vitamins and carotenoids (C) according to degree of weight loss. Changes in parameters between baseline and 6 months as defined by a reduction in BMI standard deviation score (SDS-BMI) at 6 months follow-up. Values expressed as means \pm SD. Models were adjusted for age, sex, SDS-BMI, Tanner stages and corresponding variables at baseline, changes in intake of energy and corresponding vitamins or carotenoids at 6 months, and degree of physical activity. Means in a row with different superscript letters are significantly different, *statistically significant differences in parameter changes at 6 months of treatment in relation to baseline, $P<0.05$ (general linear model with Bonferroni post hoc correction). Means for glucose, Chol, HDL-C, LDL-C, TAG, APO B/APO A1, LC lycopene and LC $\beta$-carotene were multiplied by a factor of 10. BMI, body mass index; WC, waist circumference; FMI, fat mass index; FFM, fat free mass; SBP, systolic blood pressure; DBP, diastolic blood pressure; CRP, C-reactive protein; CHOL, cholesterol; HDL-C, high-density lipoprotein cholesterol; LDL-C, low density lipoprotein cholesterol; TAG, triacylglycerol; APO A1, apolipoprotein A1; APO B, apolipoprotein B; APO B/APO A1, apolipoprotein B/apolipoprotein A1 ratio; LC, lipid-corrected. Anthropometry, $n=10 / 19 / 23$ (for SDS-BMI decrease < 0.25, SDS-BMI decrease 0.25-0.5 and SDS-BMI decrease $>0.5$, respectively); blood pressure, $n=15 / 23 / 29$; lipid profile and glucose, $n=17 / 25 / 33$; insulin, $n=4 / 7 / 5 ;$ apolipoproteins and CRP, $\mathrm{n}=6 / 10 / 19 ; \mathrm{LC} \alpha$-tocopherol, $\mathrm{n}=10 / 16 / 22$; LC retinol, $\mathrm{n}=7 / 13 / 20$; LC $\beta$-carotene, $\mathrm{n}=8 / 17 / 23$ and LC lycopene, $\mathrm{n}=10 / 17 / 23$.

weight loss goals for obese adolescents with or without associated disorders.

In addition, it is interesting to note that weight losses greater than 0.5 of SDS-BMI were related to an increase in LC $\alpha$-tocopherol and LC $\beta$-carotene levels. Furthermore, it was observed that the adolescents with intermediate decline of SDS-BMI (0.25-0.5) exhibit an increase in LC lycopene concentration at 6 months. These interactions were expected because it has been established that vitamin $\mathrm{E}$ and carotenoids may modulate several genes involved in glucose and lipid metabolism [15,16], fat storage [8] and inflammation in adipose tissue [9].
The reduction in adiposity, biochemical parameters and blood pressure observed in our study population are in line with other studies on children, showing that weight loss, as determined by a decrease in BMI or SDS-BMI, leads to an improvement in the CVD risk factor profile [29]. These results are of great importance since it has been demonstrated that atherosclerosis is initiated in childhood [30]; therefore, the changes observed in subjects' cardiometabolic profile in our study might prevent or delay the onset of the CVD associated with obesity in adulthood.

The main limitation of this study was the absence of a control group. Consequently, it has not been possible to establish the 
differences between obese and normal weight adolescents. However, as our initial aim was to analyse the evolution of the different indicators during the course of treatment and their relationship with weight loss, we consider the use of baseline values as control to be acceptable. The majority of the parameters studied showed a decrease during the intensive phase of treatment. After this phase, these parameters presented stable values or even experienced an unexpected increase. Consequently, it might be interesting to conduct a long-term study in order to evaluate the stability of the improvements achieved and optimise the duration and intensity of the programme. The periods established for medical controls should also be revised, since shorter periods between checks might favour correct observance of the instructions, especially when dealing with young population.

The present study has clearly demonstrated that lipid-corrected antioxidant vitamin and carotenoid levels changed significantly during the proposed treatment. The increase in lipid-corrected $\alpha$ tocopherol, retinol and $\beta$-carotene plasma levels was associated with a reduction in adiposity and a clinically significant improvement in cardio-metabolic profiles.

The increase in lipid-soluble antioxidant vitamin and carotenoid plasma levels could be useful in childhood obesity treatment, since lipid-corrected $\alpha$-tocopherol, $\beta$-carotene and lycopene plasma levels are related to greater weight loss. To our knowledge, no studies have been published to date which have analysed changes in lipid-soluble vitamins and carotenoids according to degree of weight loss. Consequently, we believe that these findings may be useful to establish unstudied relationships.

Further research is required to confirm the effects of lipidsoluble antioxidant vitamins and carotenoids on anthropometric indicators of adiposity, weight loss and cardio-metabolic profile in diverse populations.

\section{Statement of authorship}

M.G., R.M., G.L.B., M.M.M., A.I.C., E.M.B., A.M., J.A.M., L.M., J.M.G., J.W., J.C., A.M., M.C.L.S. and C.C. designed research; M.G. conducted research and wrote the paper; M.G. and J.M.P. analysed data; R.M., A.I.C. and M.C.L.S. did a critical review of the manuscript; C.C. and M.C.L.S. had primary responsibility for final content. All authors read and approved the final manuscript.

\section{Conflict of interest}

No conflicts of interest.

\section{Funding sources}

This work is part of the EVASYON study funded by the Spanish Ministry of Health and Consumption (Carlos III Institute of Health. FIS. Grant PI 051579).

The EVASYON study has received the award from AESAN (Spanish Agency for Food Security and Nutrition) from the Spanish Ministry of Health and Consumption to the best applied research project in 2009.

\section{Acknowledgements}

We would like to thank all of the participants in the EVASYON study group. We thank the Erasmus Mundus External Cooperation Window, Mundus 17, for the PhD grant to Marcela Guerendiain.

The EVASYON Study Group are: Coordinator: Marcos A.

Local clinical treatment teams and researchers (Principal Investigators are bolded); Granada: Campoy C., López-Belmonte G., Delgado M., Martín-Matillas M., Aparicio V., Carbonell A., Agil A.,
Silva D.R., Pérez-Ballesteros C., Piqueras M.J., Chillón P., Tercedor P., Martín-Lagos J.A., Martín-Bautista E., Pérez-Expósito M., Garófano M., Aguilar M.J., Fernández-Mayorga A., Sánchez P.; Madrid: Mar$\cos$ A., Wärnberg J., Puertollano M.A., Gómez-Martínez S., Zapatera B., Nova E., Romeo J., Díaz E.L., Pozo T., Morandé G., Villaseñor A., Madruga D., Muñoz R., Veiga O.L., Villagra A., Martínez-Gómez D., Garcia R.M., Vaquero M.P., Pérez-Granados A.M., Navas-Carretero S.; Pamplona: Martí A., Azcona C., Moleres A., Rendo T., Marqués M., Miranda M.G., Martínez J.A.; Santander: Redondo-Figuero C., García-Fuentes M., DeRufino P., González-Lamuño D., Amigo T., Lanza R., Noriega M.J.; Zaragoza: Garagorri J.M., Moreno L.A., Romero P., De Miguel P., Rodríguez G., Bueno G., Mesana $\mathrm{M}^{\mathrm{a}}$.I., Vicente G., Fernández J., Rey-López P., Muro C., Tomás C.; Data management and statistical analysis: Wärnberg J., Calle M.E., Barrios $\mathrm{L}$.

\section{References}

[1] WHO. Population-based prevention strategies for childhood obesity: report of a WHO forum and technical meeting. Geneva: World Health Organization; 2010

[2] Mathieu P, Lemieux I, Després JP. Obesity, inflammation, and cardiovascular risk. Clin Pharmacol Ther 2010;87:407-16.

[3] L'Allemand-Jander D. Clinical diagnosis of metabolic and cardiovascular risks in overweight children: early development of chronic diseases in the obese child. Int J Obes 2010;34:S32-6.

[4] Gordon-Larsen P, Adair LS, Nelson MC, Popkin BM. Five-year obesity incidence in the transition period between adolescence and adulthood: the National Longitudinal Study of Adolescent Health. Am J Clin Nutr 2004;80:569-75.

[5] Codoñer-Franch P, Boix-García L, Simó-Jordá R, del Castillo-Villaescusa C, Maset-Maldonado J, Valls-Bellés V. Is obesity associated with oxidative stress in children? Int J Pediatr Obes 2010;5:56-63.

[6] Molnar D, Decsi T, Koletzko B. Reduced antioxidant status in obese children with multimetabolic syndrome. Int J Obes 2004;28:1197-202.

[7] Yasmeen R, Jeyakumar SM, Reichert B, Yang F, Ziouzenkova O. The contribution of vitamin A to autocrine regulation of fat depots. Biochim Biophys Acta 2012:1821:190-7.

[8] Lobo GP, Amengual J, Li HNM, Golczak M, Bonet ML, Palczewski K, et al. $\beta, \beta-$ Carotene decreases peroxisome proliferator receptor $\gamma$ activity and reduces lipid storage capacity of adipocytes in a $\beta, \beta$-carotene oxygenase 1 -dependent manner. J Biol Chem 2010;285:27891-9.

[9] Gouranton E, Thabuis C, Riollet C, Malezet-Desmoulins C, El Yazidi C, Amiot MJ, et al. Lycopene inhibits proinflammatory cytokine and chemokine expression in adipose tissue. J Nutr Biochem 2011;22:642-8.

[10] Pipaliya H, Vaghasiya J. Cardio protective effect of vitamin a against isoproterenol-induced myocardial infarction. J Nutr Sci Vitaminol (Tokyo) 2012:58:402-7.

[11] Palozza P, Parrone N, Catalano A, Simone R. Tomato lycopene and inflammatory cascade: basic interactions and clinical implications. Curr Med Chem 2010; 17:2547-63.

[12] Mordente A, Guantario B, Meucci E, Silvestrini A, Lombardi EE, Martorana G et al. Lycopene and cardiovascular diseases: an update. Curr Med Chem 2011;18:1146-63.

[13] Stahl W, Junghans A, de Boer B, Driomina ES, Briviba K, Sies H. Carotenoid mixtures protect multilamellar liposomes against oxidative damage: synergistic effects of lycopene and lutein. FEBS Lett 1998;427:305-8.

[14] Calder PC, Albers R, Antoine JM, Blum S, Bourdet-Sicard R, Ferns GA, et al Inflammatory disease processes and interactions with nutrition. Br J Nutr 2009; $101: 1-45$.

[15] Zillikens MC, van Meurs JBJ, Rivadeneira F, Hofman A, Oostra BA Sijbrands EJG, et al. Interactions between dietary vitamin E intake and SIRT1 genetic variation influence body mass index. Am J Clin Nutr 2010;91: 1387-93.

[16] Brigelius-Flohé R. Vitamin E: the shrew waiting to be tamed. Free Radic Biol Med 2009;46:543-54.

[17] Tim JC, Mary CB, Katherine MF, William HD. Establishing a standard definition for child overweight and obesity worldwide: international survey. BM] 2000:320:1240.

[18] Martinez-Gomez D, Gomez-Martinez S, Puertollano MA, Nova E, Warnberg J, Veiga O, et al. Design and evaluation of a treatment programme for Spanish adolescents with overweight and obesity. The EVASYON study. BMC Public Health 2009;9:414.

[19] Tanner JM, Whitehouse RH. Clinical longitudinal standards for height, weight, height velocity, weight velocity, and stages of puberty. Arch Dis Child 1976:51:170-9.

[20] Topouchian JA, El Assaad MA, Orobinskaia LV, El Feghali RN, Asmar RG. Validation of two automatic devices for self-measurement of blood pressure according to the International Protocol of the European Society of 
Hypertension: the Omron M6 (HEM-7001-E) and the Omron R7 (HEM $637-$ IT). Blood Press Monit 2006;11:165-71.

[21] Wallach J. Interpretation of diagnostic tests. 9th ed. Philadelphia: Lippincott Williams \& Wilkins; 2011.

[22] Walldius G, Jungner I. The apoB/apoA-I ratio: a strong, new risk factor for cardiovascular disease and a target for lipid-lowering therapy - a review of the evidence. J Intern Med 2006;259:493-519.

[23] Hong K, Li Z, Wang HJ, Elashoff R, Heber D. Analysis of weight loss outcomes using VLCD in black and white overweight and obese women with and without metabolic syndrome. Int J Obes Relat Metab Disord 2005;29: 436-42.

[24] Codoner-Franch P, Lopez-Jaen AB, De La Mano-Hernandez A, Sentandreu E, Simo-Jorda R, Valls-Belles V. Oxidative markers in children with severe obesity following low-calorie diets supplemented with mandarin juice. Acta Paediatr 2010;99:1841-6.

[25] Walldius Gr, Jungner I, Aastveit Are H, Holme I, Furberg Curt D, Sniderman Allan D. The apoB/apoA-I ratio is better than the cholesterol ratios to estimate the balance between plasma proatherogenic and antiatherogenic lipoproteins and to predict coronary risk. Clin Chem Lab Med 2004;42:1355-63.

[26] Bonora E, Kiechl S, Willeit J, Oberhollenzer F, Egger G, Meigs JB, et al. Population-based incidence rates and risk factors for type 2 diabetes in white individuals: the Bruneck study. Diabetes 2004;53:1782-9.

[27] Othman EM, Kreissl MC, Kaiser FR, Arias-Loza P-A, Stopper H. Insulin-mediated oxidative stress and DNA damage in LLC-PK1 pig kidney cell line, female rat primary kidney cells, and male ZDF rat kidneys in vivo. Endocrinology 2013:154:1434-43.

[28] Wunsch R, de Sousa G, Toschke AM, Reinehr T. Intima-media thickness in obese children before and after weight loss. Pediatrics 2006;118:2334-40.

[29] Reinehr T, de Sousa G, Toschke AM, Andler W. Long-term follow-up of cardiovascular disease risk factors in children after an obesity intervention. Am J Clin Nutr 2006;84:490-6.

[30] McGill HC, McMahan CA, Herderick EE, Malcom GT, Tracy RE, Strong JP, et al. Origin of atherosclerosis in childhood and adolescence. Am J Clin Nutr 2000;72:1307s-15s. 